\title{
Comment on "The Role of Citrullinated Protein Antibodies in Predicting Erosive Disease in Rheumatoid Arthritis: A Systematic Literature Review and Meta-Analysis"
}

\author{
Shailendra Kapoor \\ Private Practice, 67 Crossing, Richmond, VA 23345, USA \\ Correspondence should be addressed to Shailendra Kapoor; shailendrakapoor@yahoo.com \\ Received 12 May 2015; Accepted 25 May 2015 \\ Academic Editor: Ruben Burgos-Vargas \\ Copyright (c) 2015 Shailendra Kapoor. This is an open access article distributed under the Creative Commons Attribution License, \\ which permits unrestricted use, distribution, and reproduction in any medium, provided the original work is properly cited.
}

The past few years have seen the identification of new biomarkers that have shown considerable promise [1] in assessing disease severity in patients with rheumatoid arthritis (RA).

Plasma neopterin is an emerging and promising marker to assess disease activity in patients with RA [2, 3]. For instance, early RA patients have a mean neopterin concentration of $8.92 \mathrm{nmol} /$ liter in comparison to a corresponding mean level of $5.63 \mathrm{nmol} /$ liter in non-RA individuals. This has been confirmed recently by Arshadi et al. who have reported accentuated neopterin levels in patients with the active stage of RA [4]. In addition, men with RA tend to exhibit high neopterin levels when compared to neopterin levels noted in women [5]. D'agostino et al. have reaffirmed this relationship by confirming the direct relationship between DAS-28 scores and serum neopterin levels [6]. Interestingly, RA patients who are negative for anti-CCP antibodies tend to have lower neopterin levels when compared to patients who are positive for anti-CCP antibodies [7]. Age at the time of initial presentation of RA also has a significant impact on neopterin expression. Macrophage derived soluble CD163 (sCD163) is another newly identified marker of disease activity in RA. For instance, patients with RA have higher sCD163 levels when compared to sCD163 levels in patients with joint diseases such as osteoarthritis [8]. Greisen et al. in a recent study have demonstrated a significant decline in sCD163 concentrations following the initiation of appropriate RA therapy. In their study, the median sCD163 level decreased to 1.28 milligrams/liter when compared to an initial median sCD163 level of 1.69 milligrams/liter noted in patients with early stage RA [9]. In fact, a close association exists between the progression of RA related radiological anomalies and sCD163 levels. Interestingly, a close association also exists between serum CRP levels and SCD163 levels [10].

Assessment of serum YKL40 levels is also emerging as a sensitive marker to evaluate disease severity in RA, especially in the early stages $[11,12]$. For instance, patients with early RA have higher YKL40 levels when compared to non-RA individuals [13]. A close association exists between the YKL40 levels and the number of joints involved in active RA. Interestingly, TGF-beta seems to have a negative impact on serum YKL40 levels [14]. Another new marker that has shown considerable promise is serum CXCL13 [15]. This has been confirmed by Meeuwisse et al. who have demonstrated accentuated rates of RA associated bone destruction in RA patients with higher CXCL13 levels [16]. Interestingly, this relationship is especially more significant in anti-CCP-2 negative patients. 
The above markers have shown considerable promise so far. Hopefully, the coming few years will see their increased use in day to day rheumatology.

\section{Conflict of Interests}

The author declares that there is no conflict of interests regarding the publication of this paper.

\section{References}

[1] A. A. Jilani and C. G. Mackworth-Young, "The role of citrullinated protein antibodies in predicting erosive disease in rheumatoid arthritis: a systematic literature review and metaanalysis," International Journal of Rheumatology, vol. 2015, Article ID 728610, 8 pages, 2015.

[2] S.-J. Zhou, Z.-X. Sun, and J. Liu, "Neopterin concentrations in synovial fluid may reflect disease severity in patients with osteoarthritis," Scandinavian Journal of Clinical \& Laboratory Investigation, vol. 73, no. 4, pp. 344-348, 2013.

[3] C. Jude, D. Dejica, G. Samasca, L. Balacescu, and O. Balacescu, "Soluble CD163 serum levels are elevated and correlated with IL-12 and CXCL10 in patients with long-standing rheumatoid arthritis," Rheumatology International, vol. 33, no. 4, pp. 10311037, 2013.

[4] D. Arshadi, B. Nikbin, Y. Shakiba, A. Kiani, A. R. Jamshidi, and M. T. Boroushaki, "Plasma level of neopterin as a marker of disease activity in treated rheumatoid arthritis patients: association with gender, disease activity and anti-CCP antibody," International Immunopharmacology, vol. 17, no. 3, pp. 763-767, 2013.

[5] G. Reibnegger, D. Egg, D. Fuchs et al., "Urinary neopterin reflects clinical activity in patients with rheumatoid arthritis," Arthritis \& Rheumatism, vol. 29, no. 9, pp. 1063-1070, 1986.

[6] L. E. D’agostino, F. Ventimiglia, J. A. Verna et al., "Correlation between DAS-28 and neopterin as a biochemical marker of immune system activation in early rheumatoid arthritis," Autoimmunity, vol. 46, no. 1, pp. 44-49, 2013.

[7] A. K. Turkyilmaz, G. Devrimsel, A. Kirbas et al., "Relationship between pulse wave velocity and serum YKL-40 level in patients with early rheumatoid arthritis," Rheumatology International, vol. 33, no. 11, pp. 2751-2756, 2013.

[8] L. Nieuwenhuizen, R. E. G. Schutgens, B. S. van Asbeck et al., "Identification and expression of iron regulators in human synovium: evidence for upregulation in haemophilic arthropathy compared to rheumatoid arthritis, osteoarthritis, and healthy controls," Haemophilia, vol. 19, no. 4, pp. e218-e227, 2013.

[9] S. R. Greisen, H. J. Møller, K. Stengaard-Pedersen et al., "Soluble macrophage-derived CD163 is a marker of disease activity and progression in early rheumatoid arthritis," Clinical and Experimental Rheumatology, vol. 29, no. 4, pp. 689-692, 2011.

[10] R. Peltomaa, L. Paimela, S. Harvey, T. Helve, and M. LeirisaloRepo, "Increased level of YKL-40 in sera from patients with early rheumatoid arthritis: a new marker for disease activity," Rheumatology International, vol. 20, no. 5, pp. 192-196, 2001.

[11] M. Morgante, O. Di Munno, and D. Morgante, "YKL 40: marker of disease activity in rheumatoid arthritis?" Minerva Medica, vol. 90, pp. 437-441, 1999.

[12] M. Kazakova, A. Batalov, T. Deneva, N. Mateva, Z. Kolarov, and V. Sarafian, "Relationship between sonographic parameters and YKL-40 levels in rheumatoid arthritis," Rheumatology International, vol. 33, no. 2, pp. 341-346, 2013.
[13] S. Kobayashi, K. Murata, H. Shibuya et al., "A distinct human CD4+ T cell subset that secretes CXCL13 in rheumatoid synovium," Arthritis \& Rheumatism, vol. 65, no. 12, pp. 30633072, 2013.

[14] J. Sellam, S. Rouanet, H. Hendel-Chavez et al., "CCL19, a B-cell chemokine, is related to the decrease of blood memory B-cells and predicts the clinical response to rituximab in rheumatoid arthritis," Arthritis \& Rheumatism, vol. 65, no. 9, pp. 2253-2261, 2013.

[15] S. Rosengren, K. C. Kalunian, A. Kavanaugh, and D. L. Boyle, "CXCL13 as a marker for outcome of rheumatoid arthritis: comment on the article by Meeuwisse et al," Arthritis \& Rheumatism, vol. 63, no. 11, pp. 3646-3647, 2011.

[16] C. M. Meeuwisse, M. P. van der Linden, T. A. Rullmann et al., "Identification of CXCL13 as a marker for rheumatoid arthritis outcome using an in silico model of the rheumatic joint," Arthritis \& Rheumatism, vol. 63, no. 5, pp. 1265-1273, 2011. 


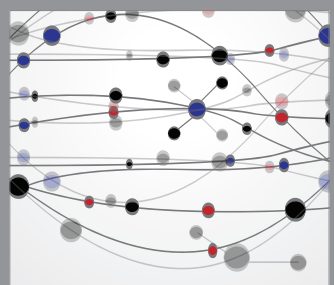

The Scientific World Journal
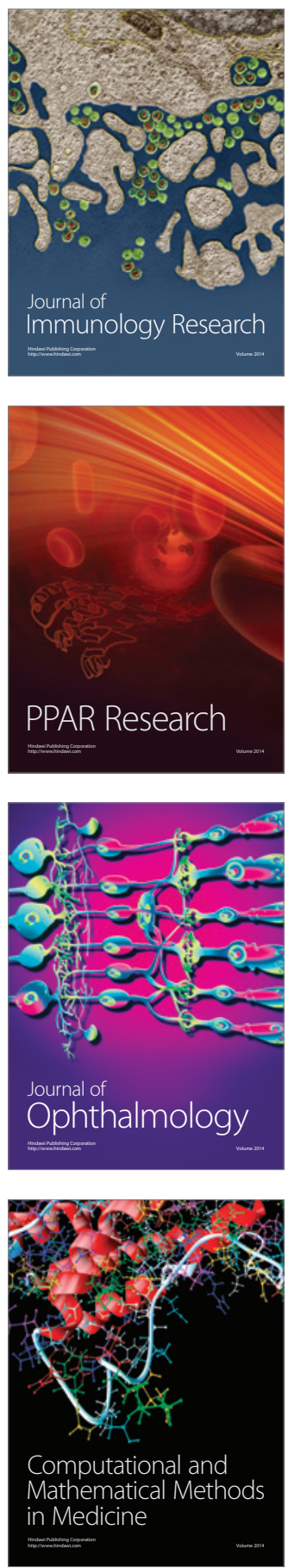

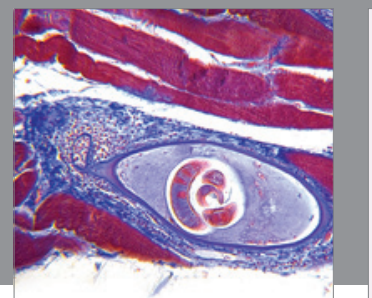

Gastroenterology

Research and Practice
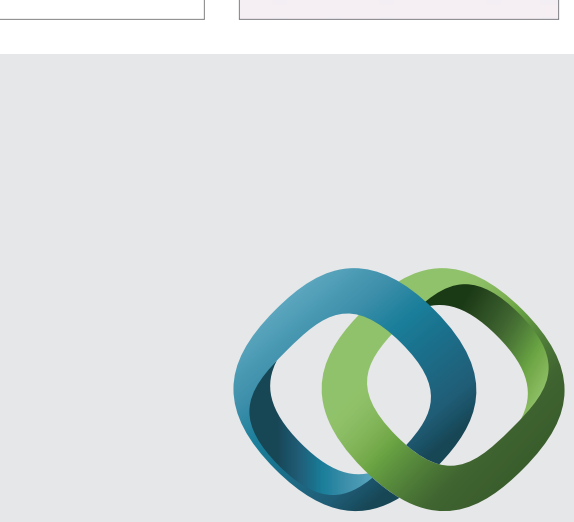

\section{Hindawi}

Submit your manuscripts at

http://www.hindawi.com
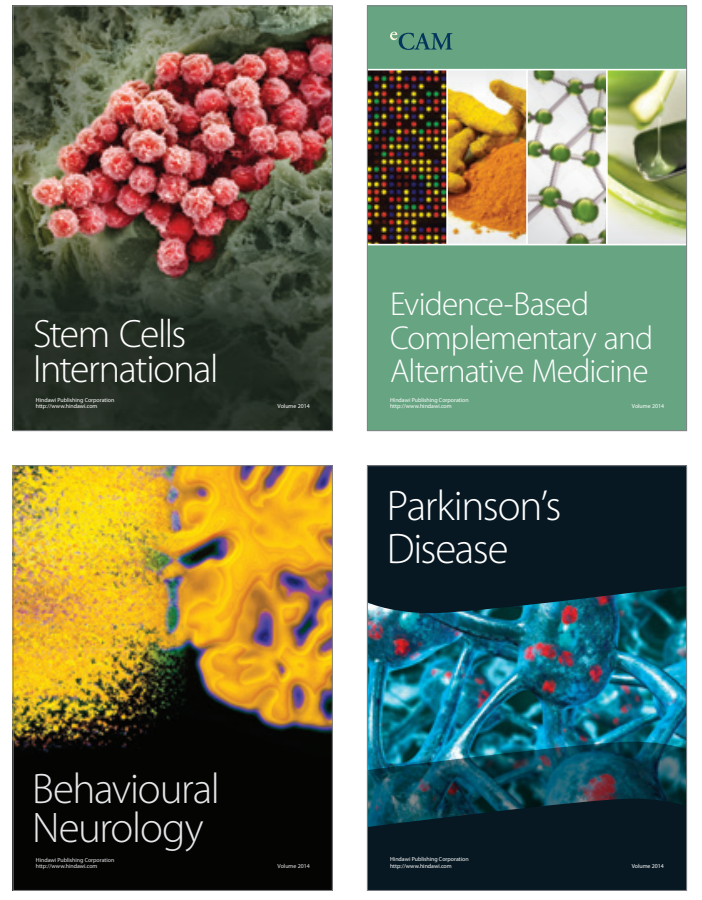
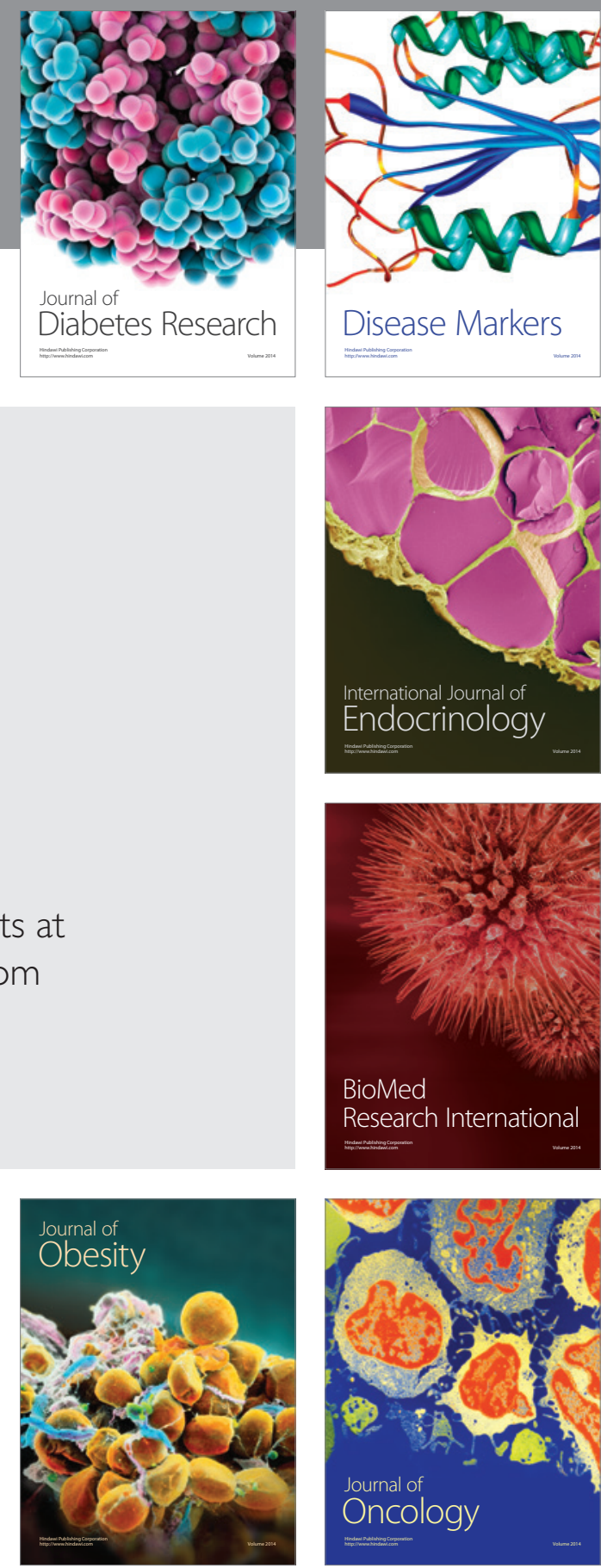

Disease Markers
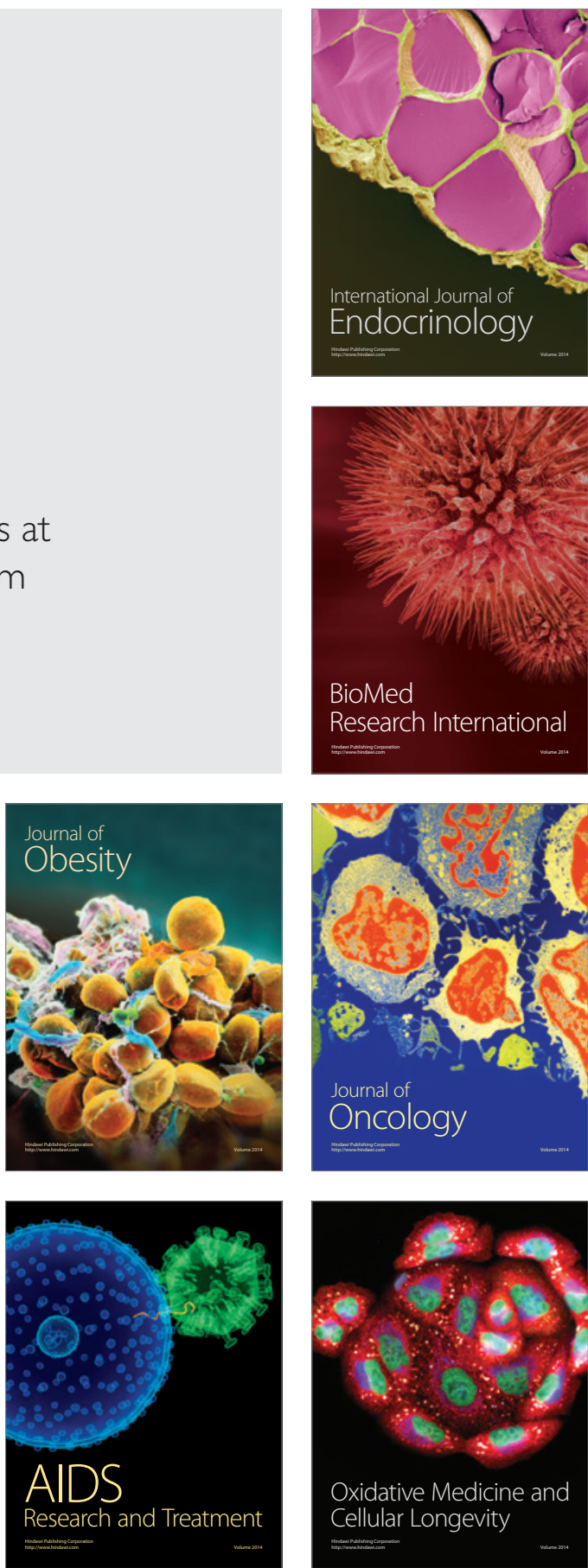